\title{
The coalescence of grammatical gender and numeral classifiers in the general classifier wota in Nepali
}

\author{
Marcin Kilarski \& Marc Tang*
}

\begin{abstract}
While nominal classification has received considerable attention, relatively little is known about cross-linguistically rare complex systems. An example is provided by Nepali (Indo-European, Indic), which possesses both grammatical gender and numeral classifiers. Our aim is to examine morphosyntactic and functional properties of the general classifier wota. Unusually, the classifier exhibits gender agreement both in its independent forms and as fused with a numeral, raising questions about its semantic and discourse functions. Our study contributes to the typology of nominal classification by proposing a functional approach to cases of complex co-occurrence of gender and classifiers.
\end{abstract}

Keywords. Nepali; nominal classification systems; grammatical gender; numeral classifiers; semantic functions, discourse functions

1. Introduction. While systems of nominal classification have received considerable attention, relatively little is known about cross-linguistically rare complex systems combining different types of nominal classification. For example, recent work on co-occurring systems of gender and classifiers has dealt with their areal distribution (Sinnemäki in press) and the possible semantic and formal configurations (Fedden \& Corbett 2017). Our aim is to examine the general classifier wota in Nepali (Indo-European, Indic) as an example of the co-occurrence of gender and numeral classifiers. We show that in a situation of stable language contact a complex system can develop involving not only multiple nominal classification systems but also fused expression of different types of classification markers. In addition, following the functional typology proposed by Contini-Morava \& Kilarski (2013), we examine the semantic and discourse functions of the general classifier. While gender and numeral classifiers display a complementary distribution of functions with respect to not only individual functions of the two systems but also the type of classified nouns, e.g., animate vs. inanimate, there is a functional overlap in the general classifier, which is used for semantic and discourse functions among both animate and inanimate nouns. In consequence, our study contributes to ongoing discussions concerning the typology and functions of nominal classification as well as the role of language contact in their development.

The paper is structured as follows. In $\S 2$ we first give an overview of gender and numeral classifier systems in South Asia as well as the language situation in Nepal, and in $\$ 3$ we describe the complex nominal classification system in Nepali, including the semantic and morphosyntactic properties of the general classifier. In $\S 4$ we discuss typological, functional and diachronic implications of the general classifier. Finally, issues which should be addressed in future research are discussed in $\S 5$.

\footnotetext{
* Authors: Marcin Kilarski, Adam Mickiewicz University, Poznań (kilarski@amu.edu.pl) \& Marc Tang, Uppsala University, Uppsala (marc.tang@lingfil.uu.se).
} 
2. Nominal classification in South Asia. Gender and numeral classifiers have a largely complementary distribution in the languages of the world. As illustrated in Figure 1, gender systems occur predominantly in Europe, Africa, South Asia and Australia, together with more isolated cases in the Americas, while numeral classifiers are found mainly in South-east and East Asia as well as parts of the Americas. South Asia belongs therefore to the areas where gender and numeral classifiers overlap in their distribution, and this is in fact also one of the areas where we find languages combining the two types of nominal classification, including Nepali. ${ }^{1}$

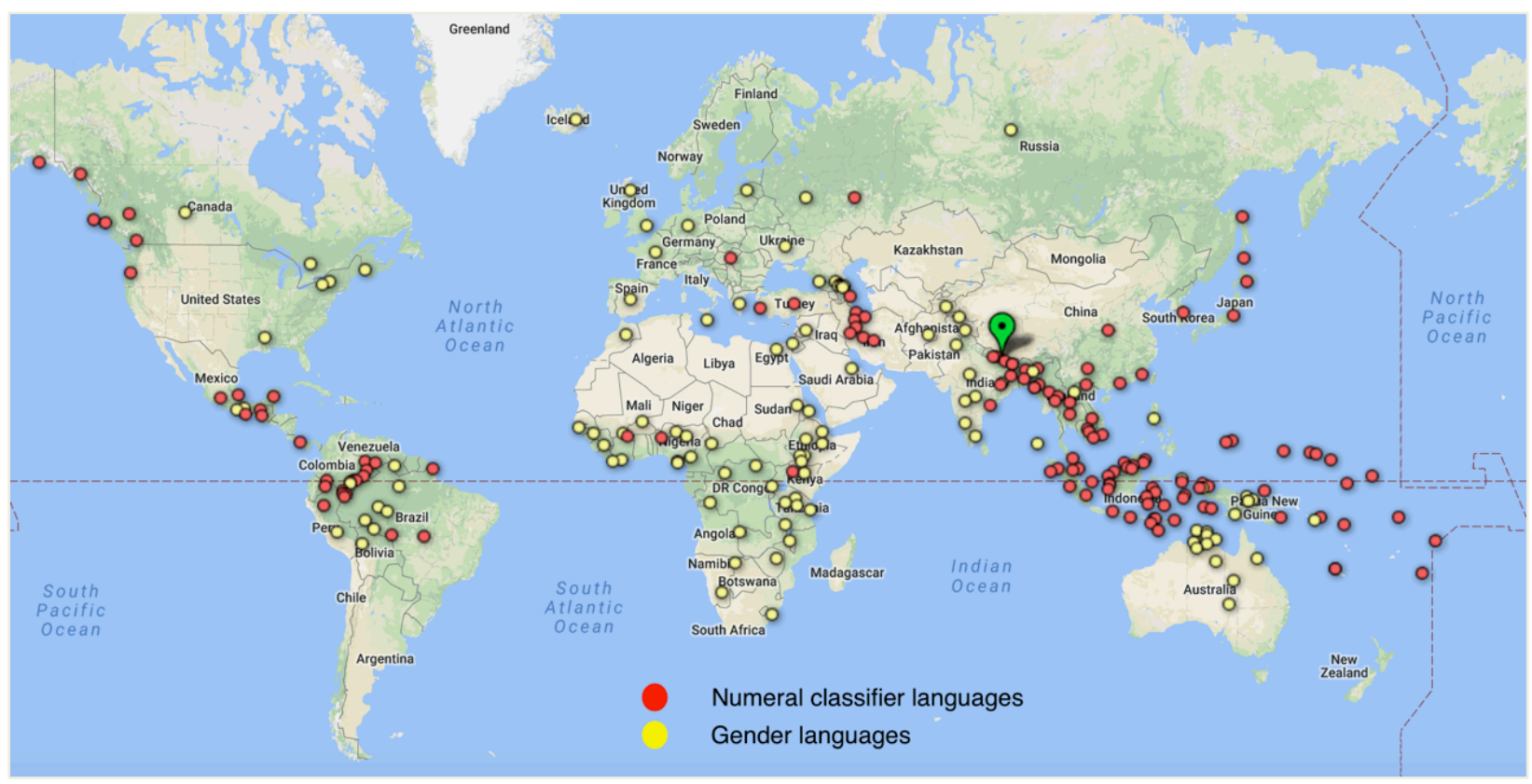

Figure 1. Distribution of gender and numeral classifiers (Corbett 2013, Gil 2013)

As regards the languages spoken in Nepal, the area constitutes a meeting point of Indo-Aryan (Indo-European) and Tibeto-Burman (Sino-Tibetan) languages (see Figure 2). While IndoEuropean languages are mainly spoken in the south-western part of the country, Sino-Tibetan languages are spoken in the north-east. In addition to Nepali, the main Indo-European languages include also Maithili and Bhojpuri, while the main Sino-Tibetan languages include Tamang, Newari and Magar.

\footnotetext{
${ }^{1}$ Four languages in Corbett (2013) and Gil (2013) combine gender and numeral classifiers, i.e., Khmu' (AustroAsiatic), Maybrat (West Papuan), Tidore (West Papuan) and Nicobarese (Car) (Austro-Asiatic).
} 


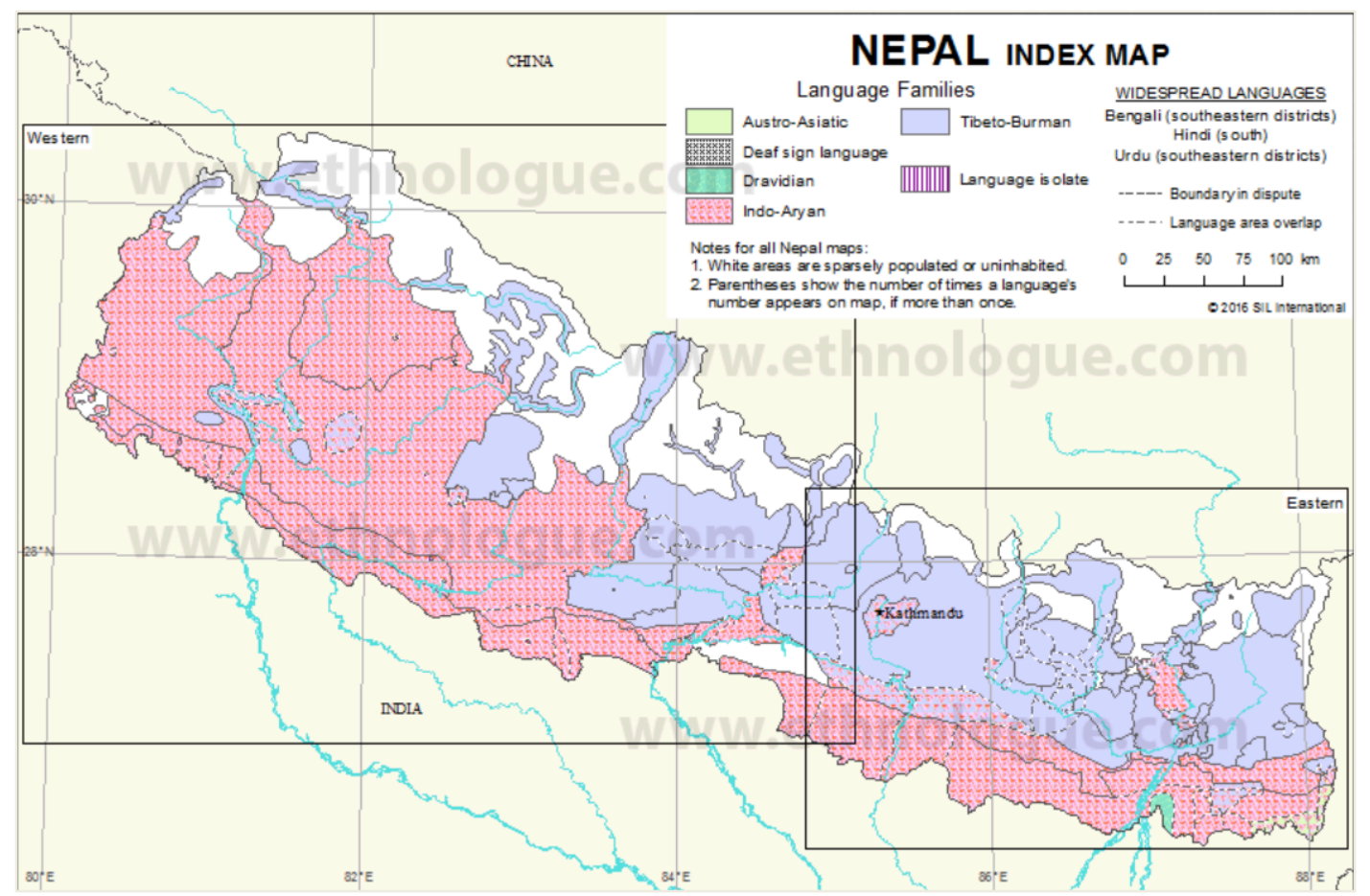

Figure 2. The languages of Nepal (Simons \& Fennig 2017)

There is complex variation in the languages belonging to the two families in terms of the distribution of gender and numeral classifiers. As illustrated in Table 1, gender is found in most IndoEuropean languages of Nepal, including Nepali, Maithili and Bhojpuri. However, as shown in more detail below, individual languages and dialects vary in the expression of gender. Similarly, languages belonging to both families show variation in terms of the presence and number of numeral classifiers, with a rich numeral classifier system found only in Newari (Kiryu 2009).

\begin{tabular}{cccc} 
Language & Language family & Gender & Numeral classifiers \\
\hline Nepali & Indo-European & yes & restricted \\
Maithili & Indo-European & restricted & restricted \\
Bhojpuri & Indo-European & yes & restricted \\
Tamang & Sino-Tibetan & no & restricted \\
Newari & Sino-Tibetan & no & yes \\
Magar & Sino-Tibetan & no & lost \\
\hline
\end{tabular}

Table 1: Distribution of gender and numeral classifiers in the languages of $\mathrm{Nepal}^{2}$

This complex distribution of nominal classification systems in the languages of Nepal can be attributed to the effects of language contact between Indo-European and Sino-Tibetan languages, where the two families provide prototypical examples of gender and numeral classifier systems, respectively (cf. Emeneau 1956, Barz \& Diller 1985).

\footnotetext{
2 For details see descriptions of the individual languages: Bhojpuri (Verma 2007), Magar (Noonan 2003:77), Maithili (Yadav 1996), Nepali (Pokharel 2010), Newari (Kiryu 2009) and Tamang (Lee 2011).
} 
3. Nominal classification in Nepali. As regards the status of gender and numeral classifiers in Nepali, there is striking disagreement in the literature. As regards gender, according to some accounts Nepali does not have grammatical gender (Corbett 1991:318, Aikhenvald 2000:379), while in others the number of genders varies between two and eleven (Clark 1977:194, Acharya 1991:99, Manders 2007:52, Pokharel 2010:40, Poudel 2010). In turn, while the commonly attested inventory of numeral classifiers includes two classifiers (human vs. non-human) (Clark 1977:82, Acharya 1991:100, Matthews 1998:54, Riccardi 2003:559-560), according to Pokharel (2010:53) Nepali has developed more than 200 numeral classifiers. This lack of agreement can be attributed to the areal variation mentioned above as well as different definitional criteria that have been used by individual authors. As will be shown in more detail below, here we adopt an analysis in terms of a two-gender system and ten numeral (sortal) classifiers.

3.1. GENDER. Following such authors as Acharya (1991:99) as well as the usage reported by the native speakers that we have consulted, ${ }^{3}$ we analyze Nepali gender in terms of a two-gender system of masculine and feminine genders. As regards gender assignment principles, Nepali has a semantic assignment system based on the distinctions of sex and animacy. Accordingly, nouns denoting female animates are feminine, with the remaining nouns, including nouns denoting male animates and the residue, assigned to the masculine gender. Gender agreement is found in verbs and possessive pronouns as well as adjectives and ordinal numbers; notably, there is no gender agreement in personal pronouns (cf. Greenberg's (1966) Universal 43). Example (1) below illustrates gender agreement in verbs and possessive pronouns with a masculine animate, feminine animate and inanimate noun:
a. mero keto nepali bolcha
my.MASC boy Nepali speak.PRS.3SG.MASC
'My boyfriend speaks Nepali.'
b. meri keti nepali bolche
my.FEM girl Nepali speak.PRS.3SG.FEM
'My girlfriend speaks Nepali.'
c. mero kitaab yahan cha
my.MASC book here be.PRS.3SG.MASC
'My book is here.'

As mentioned above, there is considerable areal variation in Nepali with regard to the presence and expression of gender. In particular, gender has been lost in varieties of Nepali spoken by bilingual Tibeto-Burman speakers, e.g., in the Darjeeling dialect, where the majority of the speakers come from a Tibeto-Burman family background (Pokharel 2010:56).

3.2. NUMERAL CLASSIFIERS. Turning to numeral classifiers, in view of the disagreement in the available descriptions of Nepali, here we analyze its numeral classifier system as consisting of ten classifiers. Thus, we argue that among the numeral classifiers analyzed by Pokharel (1997, 2010:§3.3.1), most are in fact mensural rather than sortal classifiers. Additionally, the classifiers analyzed by Pokharel were evaluated by the native speakers we have consulted in terms of active and passive knowledge. In consequence, ten numeral (sortal) classifiers have been included in

\footnotetext{
${ }^{3}$ Our study is based on data from three educated and highly mobile native speakers of Nepali, one female aged 35 and one male aged 70, both from the valley of Kathmandu, as well as another male aged 41 born in the eastern mountains of Nepal.
} 
our study, including a general classifier, a human classifier, together with inanimate classifiers based on shape, dimensionality and material. The classifiers are given in Table 2:

\begin{tabular}{ccc} 
Classifier & Meaning & Example \\
\hline jana & human & man, woman, uncle, aunt \\
wota & general & book, car, shop, telephone \\
dana & round fruits & apple, grape, orange \\
sinka & long object & noodle, bamboo \\
ghoga & long plant & maize \\
geda & grain & mustard, maize, rice \\
pana & two-dimensional & paper \\
than & two-dimensional and large & old hand-made paper \\
koso & natural capsule & banana, bean, pea \\
khili & artificial capsule & cigarette, betelnut \\
\hline
\end{tabular}

Table 2: Numeral classifiers in Nepali

The classifiers occur in the context of quantification, i.e., with numerals and quantifiers. As illustrated in Example (2) for human nouns (in a) and for non-human nouns (in b), the noun phrase ordering is Numeral-Classifier-Noun:
a. tin jana manche
three CL-HUMAN man
'three men'
three CL-ROUND.FRUIT apple
'three apples'
b. tin dana syaauu

With reference to the contradictory accounts of the size of the numeral classifier system in Nepali, the lack of agreement can be attributed to the fact that most accounts have been based on the variety spoken in the capital region, where speakers tend to use fewer classifiers, mainly the general classifier wota and the human classifier jana. In contrast, more extensive inventories are found in the east of Nepal in the area where Tibeto-Burman languages are spoken (cf. Noonan 2003:75).

In conclusion, the variation in the inventories and expression of gender and numeral classifiers in Nepali illustrates the conflicting effects of long-term contact between Indo-European and Sino-Tibetan languages, which has resulted not only in the development of numeral classifiers but also the loss of grammatical gender. Analogous changes can be observed in other IndoEuropean languages spoken in South Asia such as Assamese and Bengali.

3.3. THE GENERAL CLASSIFIER. While the classifier wota has been described in some accounts as a non-human classifier (cf. Acharya 1991:100), here we treat it as a general classifier in view of its unique semantic and morphosyntactic properties. First, similarly to general classifiers in other numeral classifier languages such as Mandarin Chinese, the classifier wota can occur with most nouns in the lexicon without referring to a specific feature. Thus, it can occur with both animate and inanimate nouns instead of the specific classifiers. Second, as illustrated in Example (3) below, the general classifier exhibits distinct morphosyntactic behavior. While the other classifiers only occur independently, the classifier wota occurs with numerals either independently (a-b) or 
as fused with a numeral (c-d). Further, what is extremely unusual about the classifier is that it exhibits gender agreement both in its independent and fused forms ((a) vs. (b) and (c) vs. (d)).
a. tin wota keto
three CL-GENERAL.MASC boy 'three boys'
b. tin woti keti
three CL-GENERAL.FEM girl
'three girls'
c. tinta keto
three.CL-GENERAL.MASC boy
'three boys'
d. tinti keti
three.CL-GENERAL.FEM girl
'three girls'

This variation in the expression of the general classifier is not only typologically rare but also appears to be characteristic of the nature of gender and numeral classifiers in Nepali in general, where gender markers either co-occur with classifiers or are fused with them as part of a complex nominal classification system.

4. Discussion. The unique morphosyntactic properties of the general classifier, together with the complex nature of gender and numeral classifiers in Nepali, allow us to evaluate cross-linguistic generalizations that have been made with reference to nominal classification systems in general. We will now discuss the implications of the classifier, focusing in turn on issues concerning the typology, functions and diachrony of nominal classification.

4.1. TYPOLOGY OF NOMINAL CLASSIFICATION. With regard to the typology of nominal classification systems, the complex system in Nepali is typologically rare due to not only the cooccurrence of two distinct types of systems, i.e., gender and numeral classifiers, but also the fusion of both types of classification markers in the general classifier. The unique status of Nepali is illustrated by the typology of complex systems proposed by Fedden \& Corbett (2017) (see Table 3).

Semantics

\begin{tabular}{|c|c|c|c|c|}
\hline & & Same & Partial overlap & Different \\
\hline \multirow{3}{*}{ Forms } & Same & $\begin{array}{c}\text { Type 1: } \\
1 \text { system (Kilivila) }\end{array}$ & $\begin{array}{c}\text { Type 4: } \\
1 \text { system } \\
\text { (Bagvalal (Nakh- } \\
\text { Dagestanian)) }\end{array}$ & $\begin{array}{l}\text { Type 7: } \\
2 \text { systems } \\
\text { (Russian) }\end{array}$ \\
\hline & Partial overlap & $\begin{array}{c}\text { Type } 2: \\
1 \text { system } \\
\text { (Latin, Mali) }\end{array}$ & $\begin{array}{c}\text { Type 5: } \\
? \\
\text { (Burmeso (isolate)) }\end{array}$ & $\begin{array}{c}\text { Type } 8: \\
2 \text { systems } \\
\text { (unattested) }\end{array}$ \\
\hline & Different & $\begin{array}{l}\text { Type 3: } \\
1 \text { system } \\
\text { (French) }\end{array}$ & $\begin{array}{l}\text { Type 6: } \\
2 \text { systems } \\
\text { (Mian) }\end{array}$ & $\begin{array}{l}\text { Type 9: } \\
2 \text { systems } \\
\text { (Paumarí) }\end{array}$ \\
\hline
\end{tabular}

Table 3: A typology of complex systems (Fedden \& Corbett 2017:37) 
Within this typology Nepali thus represents the most complex configuration in Type 5, i.e., "exactly at the mid-point between canonically one system and canonically two systems" (2017:14). In this configuration there is a partial overlap between gender and numeral classifiers in (a) semantics (both gender and classifiers categorize both animates and inanimates) and (b) formal realization (the general classifier distinguishes different agreement forms). Alternatively, if the behavior of the general classifier were not taken into account, Nepali would be classified as a Type 6 language, where there is a partial overlap in semantics but the two systems are expressed by way of different forms. In the present case, gender is realized by agreement forms and the remaining classifiers occur as independent morphemes.

4.2. FUNCTIONS OF NOMINAL CLASSIFICATION. The combined expression of the general classifier also allows us to evaluate recent proposals concerning functional properties of nominal classification systems. Within the functional typology proposed by Contini-Morava \& Kilarski (2013), two main types of functions are distinguished, i.e., semantic functions, where classification markers are used to expand the referential power of the lexicon, and discourse functions, where gender marking or the presence or choice of a classifier are used to identify and track referents, and indicate their discourse status. In terms of this typology, the functionality of the general classifier can be analyzed with reference to two different scopes. On the one hand, with respect to the functions of the two systems, gender and numeral classifiers have a largely complementary functional distribution. Three such cases can be distinguished:

- A function is expressed by only one system. For example, since classifiers are not affixed to nouns, only gender markers are used to express size distinctions among inanimates, as in jhoola 'bag' masc. vs. jhooli 'small bag (used by monks)' fem. ${ }^{4}$ In turn, due to the lack of fusional expression of gender and number, only classifiers are used to individuate nouns for quantification.

- Gender and classifiers are functionally exploited with different types of nouns, i.e., animate vs. inanimate. For example, gender marking is used to introduce, identify and disambiguate among animate referents, while classifiers are used for these functions among inanimate referents.

- Both gender and classifiers are exploited for the same function in the same category of nouns, in which case, however, they convey different meanings. For example, even though both gender and classifiers can be used to indicate the speaker's attitude towards an animate referent, they express different meanings, i.e., affection vs. respect.

On the other hand, at the micro-level, the general classifier represents an overlap of functions, where semantic and discourse functions expressed separately by gender markers and classifiers elsewhere in the language are expressed by a morphologically complex classifier. For example, as mentioned above, classifiers are used in Nepali for discourse functions, including disambiguation. However, the general classifier can be used to disambiguate among both animate and inanimate antecedents. The use of the classifier with animate referents is illustrated in Example (4), where gender marking on the general classifier and the verb in (b) helps identify one of the two referents that have been introduced in (a), without the need to repeat the nouns Floriane and Marc.

\footnotetext{
${ }^{4}$ The contrast is expressed by masculine and feminine suffixes only, without a concomitant differentiation in agreement forms. Since inanimate nouns are by default masculine, both nouns take masculine agreements.
} 
a. Floriane ra Marc meraa saathiharu hun.

Floriane and Marc my.PL friend.PL be.PRS.3PL

'Floriane and Marc are my friends.'

$\begin{array}{llll}\text { b. } \begin{array}{l}\text { Luti } \\ \text { one.CL-GENERAL.FEM }\end{array} & \begin{array}{c}\text { Londonma } \\ \text { Luta }\end{array} & \begin{array}{l}\text { bosche } \\ \text { Parisma }\end{array} & \begin{array}{l}\text { live.PRS.3SG.FEM } \\ \text { boscha }\end{array} \\ \text { one.CL-GENERAL.MASC } & \text { Paris.at } & \text { live.PRS.3SG.MASC }\end{array}$

'One lives in Kathmandu and one lives in Paris.'

Such uses of the general classifier thus provide an exception not only to the functional principles that characterize the uses of the two types of categorization in Nepali in general, as outlined above, but also to the principles which are said to motivate the distribution of gender and numeral classifiers in the languages of the world. For example, Sinnemäki (in press) interprets the complementary distribution of the two systems of nominal classification in terms of a complexity trade-off: since both systems have related functions, the fact that the two systems are rarely combined in the same language is explained in terms of economy and distinctiveness as avoidance of multiple patterns in the same functional domain. In contrast, here we illustrate the use of a fused classification marker for discourse functions in the two domains in which gender and numeral classifiers are otherwise employed, i.e., gender among animate referents and classifiers among inanimate referents.

4.3. DiACHRONY OF NOMINAL CLASSIFICATION. Finally, while in this paper we have focused on morphosyntactic and functional properties of the general classifier, the fused nature of the classifier and the complex nature of the two systems of categorization in Nepali in general provide evidence of the effects of language contact on nominal classification. As mentioned above (cf. §2 and §3), varieties of Nepali as well other languages such as Assamese and Bengali illustrate the conflicting effects of the contact between Indo-European and Sino-Tibetan languages, i.e., development of numeral classifiers and loss/reduction of gender (in some varieties of Nepali). The two types of change can be attributed to different sociolinguistic motivations, leading to conflicting outcomes in terms of morphosyntactic complexity (cf. Trudgill 2011). While the diffusion of numeral classifiers can be interpreted in terms of complexification in conditions of stable, longterm and co-territorial contact, the loss or reduction of gender systems can be viewed as a case of simplification resulting from the use of Nepali as a second language by speakers of languages without gender.

5. Conclusions. In conclusion, our study contributes to ongoing research on nominal classification by proposing a functional approach to cases of complex co-occurrence of gender and numeral classifiers in the same language. Several issues need to be addressed in future research on Nepali and other related languages of South Asia with analogous complex systems. For example, it is necessary to determine the degree of variation in the expression of gender and numeral classifiers in Nepali, in terms of not only the proximity to Sino-Tibetan vs. IndoEuropean languages but also the status of Nepali as the first or second language in urban vs. rural communities. In addition, further research is necessary on the functions of the two systems, in particular the degree to which gender and numeral classifiers contribute to the expansion of the lexicon and organization of discourse in varieties characterized by different inventories of both nominal classification systems. 


\section{References}

Acharya, Jayaraj. 1991. A descriptive grammar of Nepali and an analyzed corpus. Washington, D.C.: Georgetown University Press.

Aikhenvald, Alexandra Y. 2000. Classifiers: A typology of noun categorization devices. Oxford: Oxford University Press.

Barz, R[ichard] K. \& A[nthony] V. N. Diller. 1985. Classifiers and standardisation: Some South and South-East Asian comparisons. In David Bradley (ed.), Language policy, language planning and sociolinguistics in South-East Asia. 155-184. Canberra: Pacific Linguistics.

Clark, T.W. 1977. Introduction to Nepali: A first year course. (2nd edn.) (Edited by John Burton-Page.) London: School of Oriental and African Studies.

Contini-Morava, Ellen \& Marcin Kilarski. 2013. Functions of nominal classification. Language Sciences 40. 263-299. https://doi.org/10.1016/j.langsci.2013.03.002.

Corbett, Greville G. 1991. Gender. Cambridge: Cambridge University Press.

Corbett, Greville G. 2013. Number of genders. In Matthew S. Dryer \& Martin Haspelmath (eds.), The world atlas of language structures online. Leipzig: Max Planck Institute for Evolutionary Anthropology. http://wals.info/chapter/30.

Emeneau, M[urray] B[arnson]. 1956. India as a linguistic area. Language 32(1). 3-16. https://doi.org/10.2307/410649.

Fedden, Sebastian \& Greville G. Corbett. 2017. Gender and classifiers in concurrent systems: Refining the typology of nominal classification. Glossa: A journal of general linguistics 2(1). 1-47. http://doi.org/10.5334/gjgl.177.

Gil, David. 2013. Numeral classifiers. In Matthew S. Dryer \& Martin Haspelmath (eds.), The world atlas of language structures online. Leipzig: Max Planck Institute for Evolutionary Anthropology. http://wals.info/chapter/55.

Greenberg, Joseph H. 1966. Some universals of grammar with particular reference to the order of meaningful elements. In Joseph H. Greenberg (ed.), Universals of language. (2nd edn.) 73113. Cambridge, Mass.: MIT Press.

Kiryu, Kazuyuki. 2009. On the rise of the classifier system in Newar. In Yasuhiko Nagano (ed.), Issues in Tibeto-Burman historical linguistics. 51-69. Osaka: National Museum of Ethnology.

Lee, Sung-Woo. 2011. Eastern Tamang grammar sketch. [Unpublished MA thesis, Graduate Institute of Applied Linguistics, Dallas and SIL Nepal.].

Manders, Christopher Jay. 2007. A foundation in Nepali grammar. Bloomington, Ind.: AuthorHouse.

Matthews, David. 1998. A course in Nepali. (2nd edn.) London: School of Oriental and African Studies.

Noonan, Michael. 2003. Recent language contact in the Nepal Himalaya. In David Bradley, Randy J. LaPolla, Boyd Michailovsky \& Graham Thurgood (eds.), Language variation: Papers on variation and change in the Sinosphere and in the Indosphere in honour of James A. Matisoff. 65-88. Canberra: Pacific Linguistics.

Pokharel, Madhav P. 1997. Nepali Vakya Vyākaran [Grammar of Nepali syntax]. Kathmandu: Royal Nepal Academy.

Pokharel, Madhav P. 2010. Noun class agreement in Nepali. Kobe Papers in Linguistics 7. 4059. 
Poudel, Kedar Prasad. 2010. Gender system in Nepali and Tamang. Circle of English Teachers Journal 2(2). 7-17.

Riccardi, Theodore. 2003. Nepali. In George Cardona \& Dhanesh Jain (eds.), The Indo-Aryan languages. 538-580. London: Routledge.

Simons, Gary F. \& Charles D. Fennig (eds.). 2017. Ethnologue: Languages of the world. (20th edn.) Dallas, Tex.: SIL International. http://www.ethnologue.com.

Sinnemäki, Kaius. in press. On the distribution and complexity of gender and numeral classifiers. In Francesca Di Garbo \& Bernhard Wälchli (eds.), Grammatical gender and linguistic complexity. Berlin: Language Science Press.

Trudgill, Peter. 2011. Sociolinguistic typology: Social determinants of linguistic complexity. Oxford: Oxford University Press.

Verma, Manindra K. 2007. Bhojpuri. In George Cardona \& Dhanesh Jain (eds.), The Indo-Aryan languages. 515-537. London: Routledge.

Yadav, Ramawatar. 1996. A reference grammar of Maithili. Berlin: Mouton de Gruyter. 